\title{
SIFAT FISIK DAN MEKANIK KAYU MENGKUDU (Morinda citrifolia L) BERDASARKAN DIAMETER DAN POSISI KETINGGIAN BATANG
}

\author{
Sri Wahyuni, Fadilah H. Usman, Nurhaida \\ Fakultas Kehutanan Universitas Tanjungpura Pontianak. J1. Daya Nasional Pontianak 78124 \\ E-mail: yunis0116@gmail.com
}

\begin{abstract}
This study aims to determine the diameter and height position of noni wood that can produce the best physical and mechanical properties. The physical properties measured in this study were adjusted to their use, namely water content, density, and dimensional change using the standard British standard methods no. 373 (1999). Noni tree (Morinda citrifolia L) which is used in diameter $20 \mathrm{~cm}$ and $25 \mathrm{~cm}$. Tree felling is carried out on branches as high as branchfree and 3 parts are taken, namely the base, middle, end where each part is 1 meter in size and the distance between parts is 1 meter. The three parts of the wood (base, middle, end) are made sticks measuring $2.5 \times 2.5 \times 1 \mathrm{~m}$. after that the stick is dried until it reaches a moisture content of 12-18\%. This study used the Factorial Experiment pattern in Completely Randomized Design (CRD) with 2 treatment factors, namely a stem diameter of $25 \mathrm{~cm}, 20 \mathrm{~cm}$, and height of stem (base, middle, end) so that 18 experimental combinations were obtained. The results showed that none wood (Morinda citrifolia L) was yellow ie 8/6 chroma value $2.5 Y$ and after being sprayed with a young cream color that is 7/4 Very Pale Brown $10 \mathrm{YR}$, until the old cream is $6 / 4$ Light Yellowish Brown 10 YR based on Munsell 2000 with the best physical and mechanical properties is found in the diameter of $25 \mathrm{~cm}$ and the middle height of the stem with the value of water content $21.4690 \%$, density $0.5500 \mathrm{gr} / \mathrm{cm} 3$, shrinkage $0.1122 \%, \mathrm{MOE} 108810.37 \mathrm{~kg} /$ $\mathrm{cm} 2, M O R 408,038.90 \mathrm{~kg} / \mathrm{cm} 2, M C S 280,00 \mathrm{~kg} / \mathrm{cm} 3$ and included in the strong class category II-III.
\end{abstract}

Keywords: Diameter, mechanical properties, noni, physical, the height position of a stem

\section{PENDAHULUAN}

Mengkudu adalah salah satu tanaman yang sudah dimanfaatkan sejak lama hampir diseluruh belahan dunia namun terbatas hanya menggunakan buah dan daunnya saja, sedangkan kayunya dibuang begitu saja menjadi limbah.Umumnya kayu mempunyai sifat dan karakteristik yang berbeda antara jenis yang satu dengan yang lainnya. Demikian juga adanya perbedaan diameter, tempat tumbuh dan letak geografis serta perbedaan umur pada suatu jenis pohon, dapat menimbulkan perbedaan sifat fisik dan mekaniknya. Ada beberapa faktor yang mempengaruhi sifat fisik dan mekanik kayu anatara lain diameter dan posisi ketinggian batang. Semakin besar diameter pohon maka kekuatan kayu akan semakin tinggi terutama pada bagian pangkal pohon.

Tumbuhan ini tumbuh di dataran rendah hingga pada ketinggian $1500 \mathrm{~m}$. Tinggi pohon mengkudu mencapai 3-8 $\mathrm{m}$, memiliki bunga bongkol berwarna putih. Buahnya merupakan buah majemuk, yang masih muda berwarna hijau mengkilap dan memiliki totoltotol dan ketika sudah tua berwarna 
putih dengan bintik-bintik hitam (Djauhariya,2006). Mengkudu (Morinda citrifolia L) atau yang disebut pace maupun noni merupakan tumbuhan yang sudah dikenal lama oleh penduduk Indonesia. Pemanfaatannya lebih banyak diperkenalkan oleh masyarakat jawa yang selalu menggunakan tanaman mengkudu atau tumbuhan herbal untuk mengobati beberapa penyakit (Djauhariya, 2003).

Diameter adalah garis lurus yang melalui titik tengah suatu lingkaran. Dibidang kehutanan pengukuran diameter umumnya pada batang pohon, bagian pohon yang dipotong dan cabang. Pengukuran diameter ini penting karena merupakan dimensi yang dapat langsung diukur dan dapat menentukan luas penampang melintang pohon atau luas bidang dasar serta volume pohon.Selain diameter dan tinggi pohon, bentuk batang adalah salah satu komponen penentu volume pohon. Pertumbuhan tinggi pohon lebih dipengaruhi oleh pengaruh tempat tumbuh, sedangkan diameter pohon lebih dipengaruhi oleh kerapatan pohon. Bentuk pohon berkaitan dengan perubahan diameter batang karena perubahan tinggi pengukuran.

Penelitian ini bertujuan untuk mengetahui diameter dan posisi ketinggian batang kayu mengkudu yang dapat menghasilkan sifat fisik dan mekanik yang paling baik. Sehingga kayu mengkudu dapat dimanfaatkan secara optimal. Dimasa mendatang, penelitian ini diharapkan dapat memberi alternative substitusi kayu yang berkualitas dan dalam rangka efisiensi penggunaan kayu dan pengendalian limbah plastik.

\section{METODE PENELITIAN}

Penelitian ini dilaksanakan diLaboratorium Wood Workshop, Fakultas Kehutanan, Universitas Tanjungpura Pontianak sebagai tempat persiapan bahan baku, Laboratorium Teknologi Kayu untuk pengujian sifat fisik kayu, dan Laboratorium Politeknik Negeri Pontianak untuk pengujian sifat mekanik kayu. Penelitian dilakukan selama \pm 3 (tiga) bulan, yaitu mulai dari persiapan, pengerjaan, pengujian hingga pengolahan data.

Pohon mengkudu (Morinda citrifolia L) yang di gunakan berdiameter $20 \mathrm{~cm}$ dan $25 \mathrm{~cm}$. Penebangan pohon dilakukan pada batang setinggi bebas cabang dan diambil 3 bagian yaitu pangkal, tengah, ujung dimana setiap bagian berukur 1 meter dan jarak antar bagiannya adalah 1 meter. Kemudian ketiga bagian kayu tesebut (pangkal, tengah, ujung) dibuat stik dengan ukuran $2,5 \mathrm{~m}$ x 2,5 m x $1 \mathrm{~m}$. setelah itu stik tersebut dikering anginkan hingga mencapai kadar air 1218\%. Setelah mencapai kadar air kering angin, kemudian dibuat contoh uji tanpa membedakan bagian kayu teras dan gubalnya.Setelah dibuat contoh uji sifat fisik, kadar air,kerapatan dan perubahan dimensi, selanjutnya dibuat contoh uji sifat mekanik yaitu: MOE dan MOR serta contoh uji MCS tanpa membedakan kayu gubal dan terasnya,kemudian contoh uji tersebut dikeringanginkan sehingga mencapai 
kadar air 12-18\% selama kurang lebih 6 minggu.

Sifat fisik yang diukur dalam penelitian ini disesuaikan dengan penggunaannya yaitu kadar air, kerapatan dan perubahan dimensi, dimana pengujian dan perhitungannya menggunakan British Standard Methods no. 373 (1999), sedangkan warna berdasarkan contoh warna tanah dari Munsel (2009) meliputi : warna kayu, pengukuran kadar air, kerapatan kayu, dan perubahan dimensi (penyusutan). Pengujian sifat mekanik pada penelitian ini mengikuti British Standard Methods (1957). Nilai Klasifikasi Den Berger (1921) dijadikan sebagai nilai pembanding untuk pengujian sifat mekanik kayu Mengkudu yaitu Keteguhan Lentur Statis (Modulus of elastiticity/MOE), Keteguhan Lentur Patah (Modulus of Rupture/MOR) dan Keteguhan Tekan Sejajar Serat (Maximum Crushing Strength/MCS). Penelitian ini menggunakan pola Percobaan Faktorial dalam Rancangan Acak Lengkap (RAL) dengan 2 faktor perlakuan yaitu diameter batang sebagai faktor A yang terdiri dari 2 subfaktor dan ketinggian batang sebagai faktor B yang terdiri dari 3 subfaktor dengan ulangan sebanyak 3 kali, sehingga didapat 18 kombinasi percobaan.

HASIL DAN PEMBAHASAN Sifat fisik kayu mengkudu

Warna kayu
Hasil penelitian tentang sifat fisik kayu mengkudu (Morinda citrifolia L) menghasilkan kayu dengan perbedaan warna diantaranya yaitu diameter $25 \mathrm{~cm}$ dan diameter $20 \mathrm{~cm}$. Berdasarkan Munsell (2000) kayu mengkudu berdiameter $25 \mathrm{~cm}$ berwarna kuning yaitu $8 / 6$ value chroma $2.5 \mathrm{Y}$, sedangkan diameter kayu $20 \mathrm{~cm}$ berwarna krem muda yaitu 7/4 Very Pale Brown 10 YR sampai krem tua yaitu 6/4 Light Yellowish Brown 10 YR.

\section{Kadar air}

Nilai rerata kadar air yang tertinggi terdapat pada kayu dengan diameter 25 cm pada bagian tengah kayu mengkudu yaitu $21,8328 \%$ dan nilai kadar air terendah terdapat pada diameter kayu $25 \mathrm{~cm}$ pada bagian pangkal kayu mengkudu yaitu 17,33287\%. Menurut Dany (2007), menyatakan bahwa kadar air pada kayu pasir-pasir cenderung meningkat dari pangkal kebagian tengah dan menurun kebagian ujung kayu.Kadar air kayu setelah dikeringkan berkisaran antara 15-18\%, nilai tersebut sesuai nilai kadar air yang dikeluarkan oleh Oey Djoen Seng (1990), kadar air akhir yang dapat dicapai melalui pengeringan alami yang disebut kadar air kering udara , kadar air akhir yang dapat dicapai melalui pengeringan alami yang disebut kadar air kering udara di Indonesia kadar ini berkisaran antara 12 $-20 \%$. 


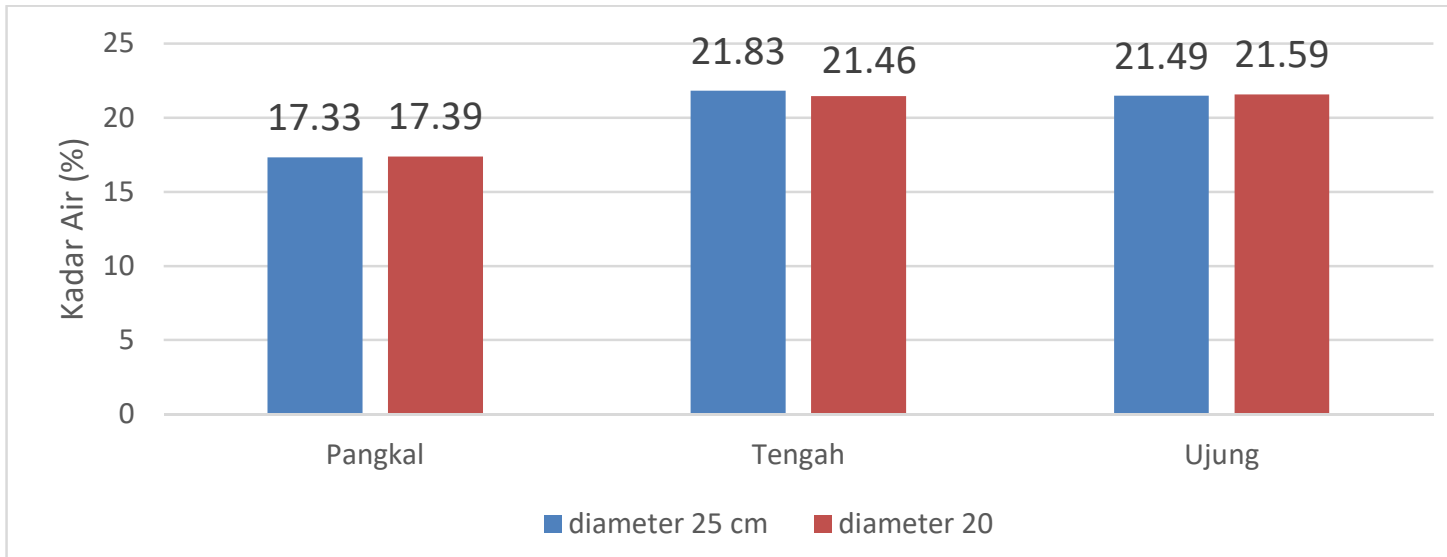

\section{Kerapatan}

Gambar 1 Histogram Nilai Kadar Air (\%) (Histogram of Water Value (\%))

Nilai rerata kerapatan yang tertinggi terdapat pada kayu dengan diameter $25 \mathrm{~cm}$ pada bagian pangkal kayu mengkudu yaitu $0,7460 \mathrm{gr} / \mathrm{cm}^{2}$ dan nilai kerapatan terendah terdapat pada diameter kayu $25 \mathrm{~cm}$ pada bagian tengah kayu mengkudu yaitu 0,5346 $\mathrm{gr} / \mathrm{cm}^{2}$.

Nilai kerapatan mengkudu pada posisi pangkal batang lebih tinggi dibandingkan pada posisi ujung batang. Hal ini sesuai pendapat Pandit (1989) perbedaan antara kerapatan kayu yang berdekatan tergantung pada tipe organisasi atau susunan dinding sel dalam kayu tarik. Serabut - serabut gelatinous yang berdinding sel tebal dapat menaikkan keraptan kayu sebesar $30 \%$ diatas kayu normal. Untuk yang berdinding sel tipis angka ini berkisaran antara $10-15 \%$.

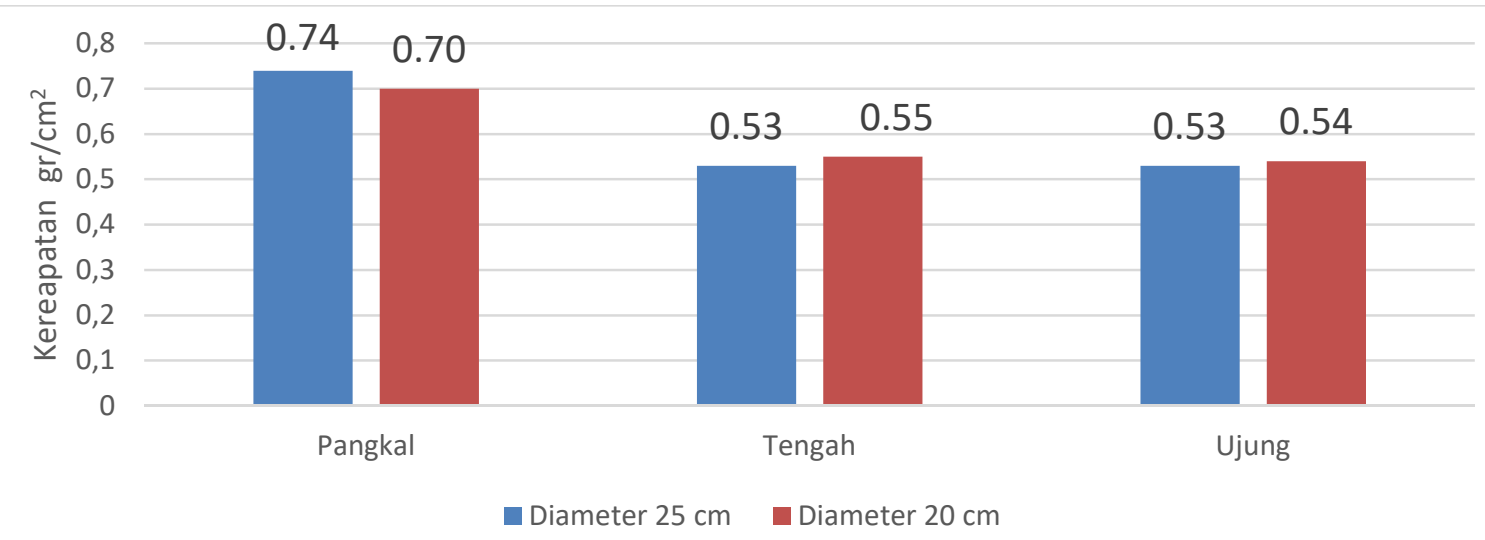

Gambar 2 Histogram Nilai Kerapatan gr/ $\mathrm{cm}^{2}$ (Histogram of Density Value gr $/ \mathrm{cm} 2$ )

Penyusutan

Nilai rerata penyusutan yang terendah terdapat pada kayu dengan diameter $25 \mathrm{~cm}$ pada bagian ujung kayu mengkudu yaitu $0,0525 \%$ dan nilai penyusutan tertinggi terdapat pada diameter kayu $25 \mathrm{~cm}$ pada bagian pangkal kayu mengkudu yaitu 0,3082 $\%$. 


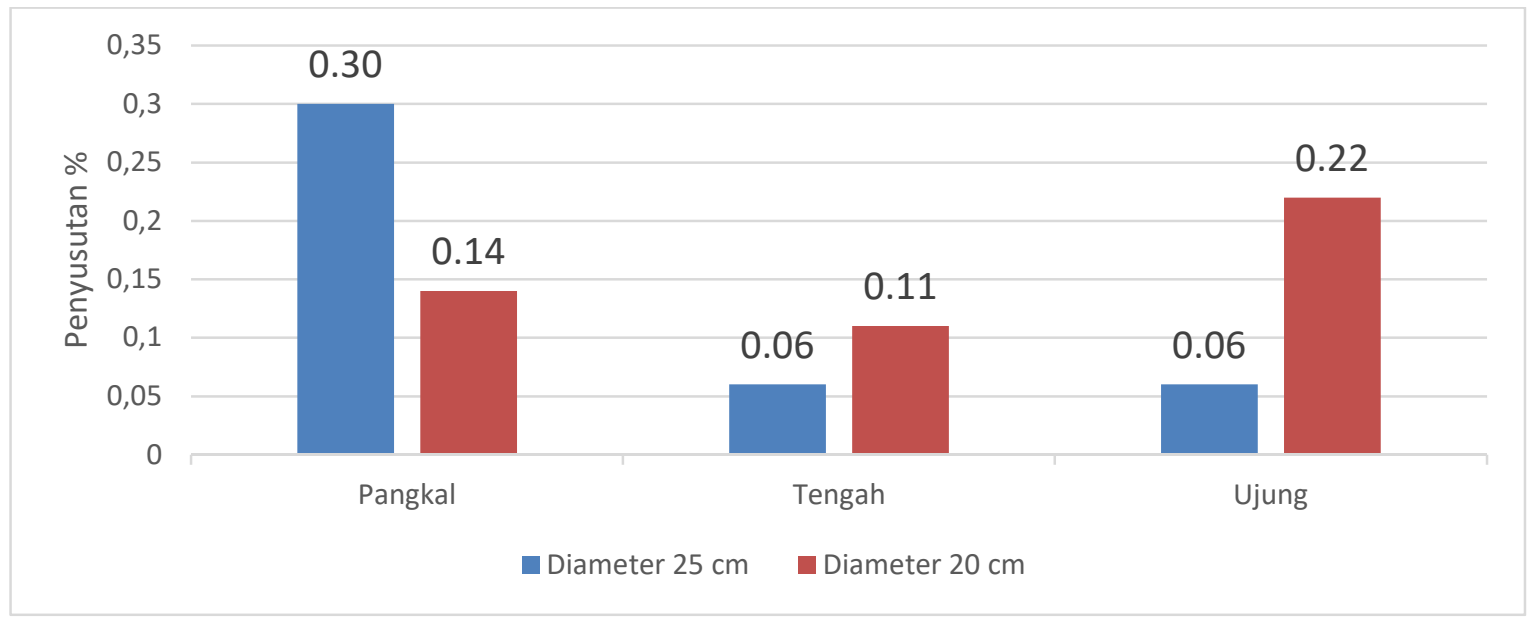

Gambar 3 Histogram Nilai Penyusutan \%

(Figure 3 Histogram Depreciation Value\%)

Penyusutan terjadi karena adanya sifat higroskopis selulosa, komponen utama kayu yang bertambah akibat air yang di absorbsi oleh selulosa sehingga meregangkan struktur selulosa kayu dan sebaliknya penyusutan kayu disebabkan oleh berkurangnya volume kayu ketika air ditiadakan dan struktur selulosa yang tidak teratur menyusut.

Sifat mekanik kayu mengkudu
Keteguhan Lentur Statis / modulus elasticity (MOE)

Nilai rerata MOE kayu mengkudu berkisar antara 108810,37 - 40294,26 $\mathrm{kg} / \mathrm{cm}^{2}$ yang terdiri dari bagian pangkal pada dimeter $25 \mathrm{~cm}$ yaitu dengan nilai yang terendah dengan angka 40294,26 $\mathrm{kg} / \mathrm{cm}^{2}$ sedagkan nilai tertinggi dengan angka $108810,37 \mathrm{~kg} / \mathrm{cm}^{2}$ yaitu pada bagian tengah dengan diameter $20 \mathrm{~cm}$.

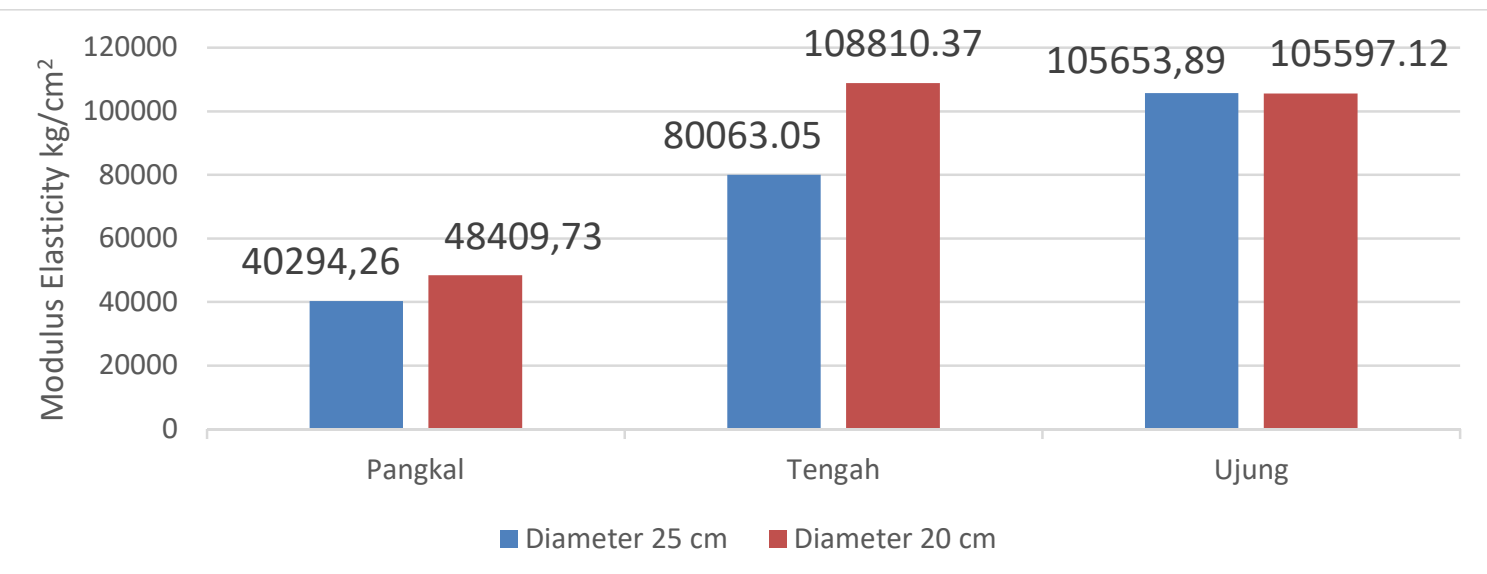

Gambar 4 Histogram Nilai Modulus elasticity $\mathrm{kg} / \mathrm{cm}^{2}$ (Histogram Value of Modulus elasticity $\mathrm{kg} / \mathrm{cm} 2$ ) 
Secara keseluruhan batang kayu mengkudu pada bagian pangkal memiliki nilai yang lebih tinggi dibandingkan dengan bagian tengah dan ujung, dengan kata lain bagian pangkal sifat mekaniknya lebih baik dibandingkan dengan bagian tengah dan ujung. Menurut Endy Dkk Hal tersebut dikarenakan terdapat susunan sel bagian pangkal yang rapat dan tebal, hal tersebut sesuai dengan pendapat
Krisdianto (2006) bahwa dinding serat ditemukan dibagian pangkal dan menipis tajam kebagian ujung.

Keteguhan Lentur Patah (modulus of repture (MOR)

Nilai rerata MOR yang tertinggi terdapat pada kayu mengkudu dengan diameter $20 \mathrm{~cm}$ pada bagian tengah kayu mengkudu yaitu $408038,9 \mathrm{~kg} / \mathrm{cm}^{2}$ dan nilai $\mathrm{MOE}$ terendah terdapat pada diameter kayu $20 \mathrm{~cm}$ pada bagian ujung kayu mengkudu yaitu $105597,1 \mathrm{~kg} / \mathrm{cm}^{2}$.

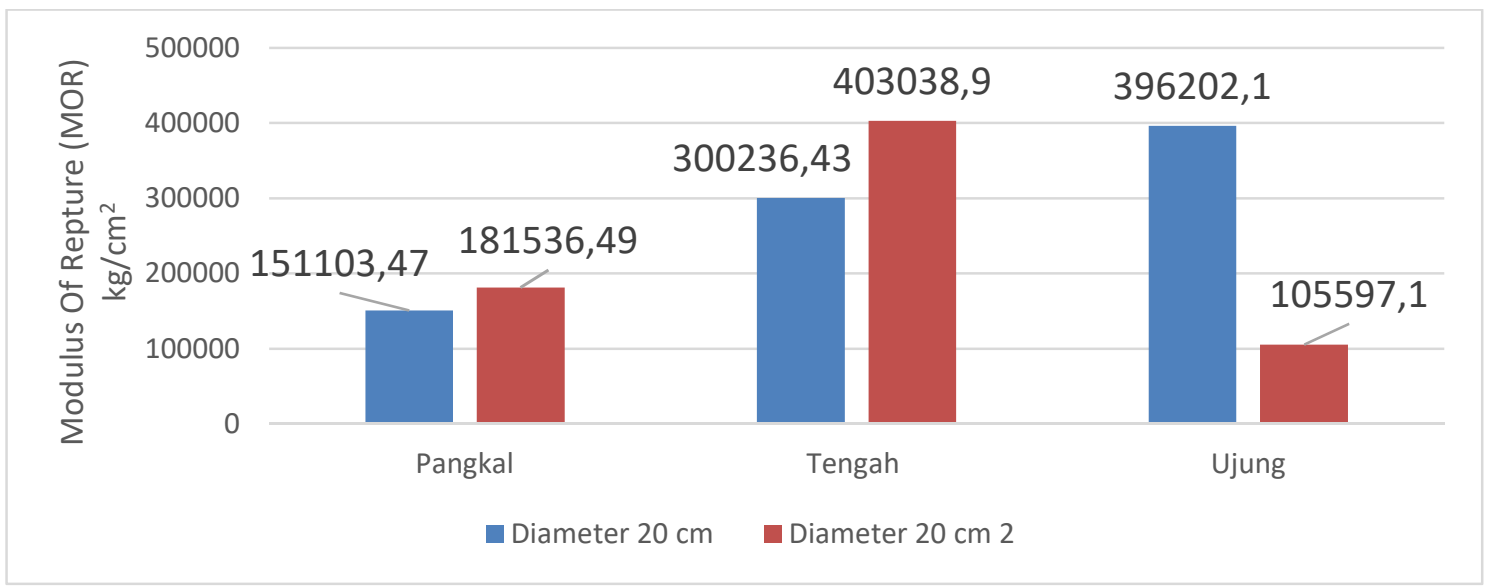

Gambar 5 Histogram Nilai Modulus Of Repture $\mathrm{kg} / \mathrm{cm}^{2}$ (Histogram Modulus of Repture $\mathrm{kg} / \mathrm{cm}^{2}$ )

Nilai MOR berhubungan erat dengan nilai rerata MOE dan kerapatan, terbukti dengan peningkatan dan penurunan nilai yang relative sama. Hubungan antara kerapatan dengan MOE dan MOR membentuk garis linier positif, yang berarti semakin tinggi keraptan maka semakin tinggi pula MOE dan MOR, begitupun sebaliknya (Wardhani, 2005). Haygreen dan Bowyer (1989) menyatakan bahwa pada saat kayu mengering dibawah titik jenuh serat, sebagian besar kekuatan dan sifat elastisnya bertambah. Hal ini disebabkan karena saat air keluar dari dinding sel, molekul yang berantai panjang bergerak saling mendekat dan menjadi terikat lebih kuat.

Keteguhan Tekan Sejajar Serat (Maximum Cruishing Strght/MCS)

Nilai rerata MCS yang tertinggi terdapat pada kayu mengkudu dengan diameter $20 \mathrm{~cm}$ pada bagian pangkal kayu mengkudu yaitu $309,33 \mathrm{~kg} / \mathrm{cm}^{3}$ dan nilai MCS terendah terdapat pada diameter kayu $25 \mathrm{~cm}$ pada bagian pangkal kayu mengkudu yaitu171,87 $\mathrm{kg} / \mathrm{cm}^{3}$. 


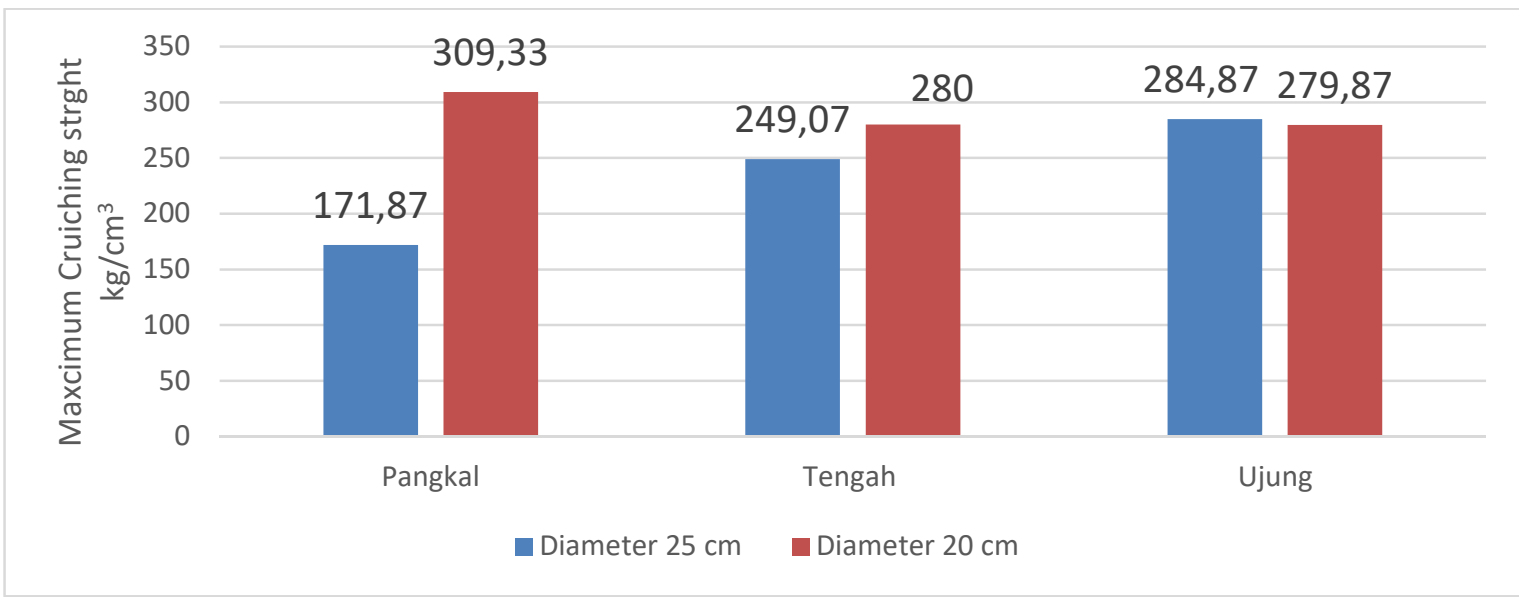

Gambar 6 Histogram Nilai Maxcimum Crushing Strght kg/ $\mathrm{cm}^{3}$ (Histogram Maximum Crushing Strength value $\mathrm{kg} / \mathrm{cm}^{3}$ )

Menurut (Nurcahyo, 2006) struktur anatomi kayu menyebabkan kenaikan berat jenis dan kerapatan, sehingga hal ini menyebabkan sifat mekanik kayu mengkudu pada keadaan kering udara kekuatan kayu lebih tinggi dibandingkan kayu normal.

\section{Kesimpulan}

Berdasarkan hasil penelitian tentang sifat fisik dan mekanik kayu (Morinda citrifoliaL) mengkudu berdasarkan diameter dan posisi ketinggian batang, dapat diambil kesimpulan sebagai berikut:

1. Kayu mengkudu mempunyai warna yang cukup cerah yaitu berkisar antara warna kuning yaitu $8 / 6$ value chroma $2.5 \mathrm{Y}$, setelah dioven mengalami perubahan warna yaitu menjadi krem muda yaitu $7 / 4$ Very Pale Brown 10 YR, sampai krem tua yaitu 6/4 Light Yellowish Brown 10 YR berdasarkan Munsell 2000.

2. Posisi ketinggian batang kayu mengkudu sangat berpengaruh nyata terhadap nilai kadar air, kerapatan., MCS dan tidak berpengaruh nyata pada nilai MOE,MOR dan
penyusutan.Faktor diameter pohon dan interaksi kedua faktor tidak berpengaruh nyata terhadap semua nilai kecuali nilai MCS.

3. Diameter dan posisi ketinggian batang kayu mengkudu yang dapat menghasilkan sifat fisik dan mekanik terbaik terdapat pada diameter $25 \mathrm{~cm}$ dan ketinggian batang bagian tengah yaitu dengan nilai kadar air 21,4690 $\%$, kerapatan $0,5500 \mathrm{gr} / \mathrm{cm}^{3}$, penyusutan $\quad 0,1122 \%$, MOE 108810,37 kg/cm ${ }^{2}$, MOR $408.038,90 \mathrm{~kg} / \mathrm{cm}^{2}$, MCS 280,00 $\mathrm{kg} / \mathrm{cm}^{3}$ dan termasuk dalam kategori kelas kuat II - III.

\section{Saran}

Kayu mengkudu dapat digunakan sebagai bahan baku kayu untuk mengatasi kelangkaan bahan baku konstruksi, karena tingkat pertumbuhanya yang sangat cepat, dan termasuk kategori kelas kuat II-III.

\section{DAFTAR PUSTAKA}

British Standard,1957. Methods of Testing Small Clear Speciment of Timber Serial Bs 373, British Standard Institution, London. 
Sunandar Ahmad Dany,2007. Sifat Fisik dan Mekanik Kayu PasirPasir (xanthopyllum sp). Balai Penelitian Kehutanan Aek Nauli. Departemen Kehutanan.

Djauhariya E, 2003. Mengkudu (Morinda citrifolia L) Tanaman Obat Potensial. Balai Penelitian Tanaman Rempah dan Obat. $J$ Pengemb. Tek. TRO.15(1) : 1-16.

Djauhariya E, Rahardjo M, Ma'mun. 2006. Karakterisasi Morfologi dan Mutu Buah Mengkudu. Bul. Plasma Nutf. $12: 1$.

Haygreen, G.J. dan Bowyer, L.J. 1993. Hasil Hutan Dan Ilmu Kayu Suatu Pengantar. Gajah Mada University press. Yogyakarta.

Krisdianto,2006. Anatomi dan Kualitas Serat Lima Jenis Kayu Kurang DiKenal Dari Lengkong Suka Bumi. Jurnal Penelitian Hasil Hutan. Bogor.

Munsell, 2009. Soil-Color-Chart. Produced by Munsell Color.
Quoted In Prat From U. S. Agriculture Handbook.

Nurcahyo,2006. Identifikasi Jenis Kayu Sebagai Bahan Baku Bagian Lunas Kapal Nelayan Tradisioanl. Skripsi. Fakultas Kehutanan Institut pertanian Bogor.

Oey Djoen Seng, 1964.Berat jenis dari jenis-jenis kayu Indonesia dan pengertian beratnya kayu untuk keprluan praktek. Pengumuman No. 1. Lembaga penelilitian Hasil Hutan Bogor.

Pandit,1989. Anatomi Pertumbuhan dan Kualitas Kayu. Bidang Studi Ilmu Pengetahuan Kehutanan Program Pasca Sarjana. Institut Pertanian Bogor.

Wardhani, I.Y. 2005. Kajian sifat dasar pemadatan Bagian dalam kayu kelapa (cocos nucifera L). Sekolah Pasca sarjana, Institut pertanian bogor (tidak dipublikasikan). 